\title{
LA RESPONSABILIDAD DEL ANALISTA FINANCIERO COMO TERCERO DE CONFIANZA
}

\section{THE RESPONSIBILITY OF SECURITIES ANALYSTS AS GATEKEEPERS}

Adriana Carolina Combatt Fandiño*

Fecha de recepción: 25 de febrero de 2009 Fecha de aceptación: 14 de abril de 2010

* Abogada de la Pontificia Universidad Javeriana; especialista en Derecho Contractual de la Universidad Colegio Mayor de Nuestra Señora del Rosario; Máster en Derecho Privado de la Universidad Carlos III de Madrid; actualmente abogada de la firma Alberto Preciado \& Asociados Abogados. Contacto: adrianacombatt@gmail.com 


\section{RESUMEN}

Los escándalos corporativos en los Estados Unidos y en Europa han llamado la atención sobre la importancia que tienen los terceros de confianza o gatekeepers en el mercado, provocando la necesidad inminente de regular su actividad y responsabilidad. En los casos donde existe una relación contractual es claro cómo encauzar su responsabilidad, existiendo ambigüedad en la forma legal de proceder cuando ésta no existe. Este artículo analiza las distintas posiciones que se han sostenido y propone una visión unificada para regular la actividad y responsabilidad del analista financiero como tercero de confianza, ante la ausencia de una relación contractual. Se argumenta, sobre la base del análisis de derecho comparado, que el analista como tercero de confianza será responsable ante terceros cuando éstos formen parte del grupo de personas a las que va dirigida la información o se preveía que la podían obtener, y el daño se cause en la realización de la operación para la cual fue elaborada. En los sistemas de derecho civil, la responsabilidad extracontractual es el instrumento más eficaz para resarcir estos casos.

Palabras clave: analista financiero, tercero de confianza, gatekeeper, información o signos de mercado, responsabilidad extracontractual.

Palabras clave descriptor: Analista financiero, responsabilidad extracontractual, derecho civil.

\section{ABSTRACT}

Corporate scandals in the United States and Europe have drawn attention to the importance of "gatekeepers" in the market, causing the imminent need to regulate their activity and responsibility. In cases where there is a contract, is clear how to manage the responsibility, ambiguity exists in the legal way to proceed if it does not exist. This article discusses the different positions that have been held so far, and proposes a unified vision for regulating the activity and responsibility of the financial analyst as a gatekeeper, in the absence of a contractual relationship. It is argued, on the basis of comparative law analysis, that the analyst as a gatekeeper will be liable before third parties when they are part of the group of persons to whom the information was provided or that reasonably could obtain it, and the damage is cause in the operation for which the information was developed. Torts are the most effective instrument for these cases in civil law systems.

Key words: financial analyst, gatekeeper, information or market signs, torts.

Key words plus: Financial Analyst, Extra-Contractual Responsibility, Civil Law 


\section{INTRODUCCIÓN}

Un inversor sin experiencia en el mercado de valores encuentra en Internet un informe de un conocido analista financiero, donde plasma predicciones favorables sobre los valores futuros de una empresa y hace recomendaciones positivas de inversión. Confiando en dicha información y en la calificación del experto, el inversor realiza la transacción recomendada empleando todos sus ahorros, pero pocos días después la empresa se declara en quiebra.

¿Es responsable el analista ante el inversor por su pérdida económica? ¿Es responsable en general el analista por la información profesional que ofrece o simplemente se trata de consejos o sugerencias sin trascendencia legal? ¿Puede tener certeza el inversor cuando toma una decisión con base en la información que proporciona el analista?

Las crisis financieras y contables y los grandes escándalos corporativos en los Estados Unidos y Europa de principios del año 2000 -Enron, WorldCom, Parmalat- han llamado la atención sobre la importancia que tienen los terceros de confianza o gatekeepers en el mercado y provocado la reacción inmediata de los gobiernos para regular su actividad y determinar sus responsabilidades. Sistema regulatorio que, dicho sea de paso, está actualmente en entredicho por la increíble estafa piramidal de Madoff Investment Securities, que salió a la luz pública a finales del año 2008.

Entre estos terceros de confianza se destacan los analistas de inversiones, profesionales especializados cuya actividad consiste básicamente en la investigación y recogida de información de las sociedades cotizadas para analizarla, procesarla y transformarla en informes escritos que generalmente contienen predicciones de beneficios de la compañía analizada, estimaciones de precios y recomendaciones objetivas de inversión. Es decir, el producto final de su trabajo es también la información, un producto con características especiales que puede llevar a la responsabilidad desmedida del analista.

Los inversores, por su parte, especialmente los minoristas sin relación contractual alguna con los analistas confían -justificada o injustificadamente - en estas recomendaciones y, en general, en toda la información y "signos" que estos profesionales han transmitido al mercado y con base en ellos adoptan decisiones o realizan transacciones como consecuencia de los cuales resultan perjudicados. Es aquí donde se presenta el núcleo de este trabajo, es indispensable saber qué puede hacer el inversor ante estos escenarios, determinando si el analista es o no responsable por los daños causados, frente a quién y en qué medida.

En los casos donde existe una relación contractual, la responsabilidad del analista está reconocida en todos los ordenamientos sin discusión alguna, pero en el caso contrario, no está claro el rumbo que se va a seguir. Hasta el momento, la literatura ha ofrecido una serie de soluciones, posiblemente 
efectivas pero dispersas y casuísticas, para los casos donde no hay un contrato de por medio. Por consiguiente, esta investigación pretende analizar las distintas posiciones que se han sostenido hasta el momento y ofrecer una visión unificada que pueda servir de guía para regular la actividad y responsabilidad del analista como gatekeeper en el mercado.

No existe una regulación clara y generalizada, ni estudios doctrinales sobre el tema específico de la responsabilidad del analista de inversiones como tercero de confianza en el mercado. Los países del Common Law sin embargo, además de iniciar la discusión y aplicación de los daños puramente económi$\cos$, han desarrollado el tema de la responsabilidad por informaciones falsas, erróneas e inexactas tanto legislativa como jurisprudencialmente, doctrina que puede ser aplicada a los países de derecho civil cambiando el enfoque clásico de la culpa. La relevancia de las predicciones de los analistas de inversiones ha dado lugar a una amplia literatura, que se enfoca principalmente en los métodos de análisis, las recomendaciones de consenso, el valor de las predicciones y el error en las mismas. No obstante la abundante literatura, existe un vacío sobre el tema de la responsabilidad del analista financiero cuando actúa como tercero de confianza o gatekeeper en el mercado. Existen algunos avances alentadores, pero escasos en el derecho anglosajón ${ }^{1}$, así como esfuerzos aislados para explicar el desarrollo de la actividad del analista de inversiones y su responsabilidad ${ }^{2}$.

Dentro de este contexto, resulta importante responder los siguientes interrogantes: ¿Cuándo actúa el analista de inversiones como tercero de confianza en el mercado? ¿Cuál debe ser su régimen de responsabilidad por los daños y perjuicios provocados por el contenido de sus informes de análisis? ¿Cuál es el medio más adecuado para encauzar esta responsabilidad? ¿Quiénes son los terceros frente a los cuales debe responder? ¿Cuándo está justificada su confianza?

Con este trabajo se pretende dar los primeros pasos para el establecimiento de un marco general, que pueda servir de referencia para la resolución de los problemas que surjan con ocasión del ejercicio de la actividad del analista financiero como gatekeeper, llenando en cierta medida el vacío existente, además de establecer un enfoque hacia los sistemas del derecho civil donde,

1 Reinier H. KraAkman. Gatekeepers: The anatomy of a third-party enforcement strategy, 1 Journal of Law, Economics, and Organization, $n^{\circ} 2$ (1986); S., CHOI, Market lessons for gatekeepers, 3 Northwestern University Law Review, n 92 (1998); A. Hamdani, Gatekeeper liability, (Harvard Law School, John M. Olin Center for Law, Economics, and Business, Discussion paper n ${ }^{\circ} 442,2003$ ); F. Partnoy, Strict liability for gatekeepers: A reply to professor Coffe, (University of San Diego School of Law and Economics Research Paper Series, Paper 5, 2004); Geoffrey F. Aronow \& Ehrman LLP. Heller, You are your brother's keeper: The increasing costs of aiding the misconduct of others, (Bloomberg LP, 2005).

2 J.C. CoffE. Gatekeepers the professions and corporate governance (Oxford; New York: Oxford University Press, 2006). 
en contraste con los sistemas de derecho consuetudinario, existe una cláusula abierta de responsabilidad y un deber genérico de cuidado.

El capítulo primero inicia describiendo las funciones y actividades características del analista financiero así como el principal obstáculo para su independencia y la objetividad de sus investigaciones. En el siguiente, se analiza la regulación básica de su actividad en los Estados Unidos, la Unión Europea y España; así como los códigos éticos y de conducta, que actualmente pueden tener más importancia que la regulación estatal. En los capítulos 3 y 4 se define cuándo actúa el analista de inversiones como tercero de confianza en el mercado, que hace que sea considerado un gatekeeper, cuál es el panorama general de su responsabilidad y se sostiene por qué el mejor medio para encauzarla es la responsabilidad civil extracontractual basada no sobre la culpa y la previsibilidad sino en un deber de cuidado específico. En el capítulo 5 se revisan los elementos fundamentales de la responsabilidad extracontractual en el contexto de la actividad del analista, quiénes son los potenciales terceros perjudicados por una información inexacta, errónea o falsa. Finalmente se discute la eficacia de los límites de la responsabilidad del analista mediante cláusulas de exclusión o disclaimers, y las advertencias generales o warnings, para terminar con las conclusiones generales.

\section{EL ANALISTA FINANCIERO}

\subsection{Funciones y actividades del analista financiero}

Los gatekeepers dentro del contexto del mercado de capitales son profesionales que, respaldados por su reputación, proveen servicios de verificación o certificación, protegiendo los intereses de los inversores y asegurando a éstos la calidad de las "señales" enviadas por las corporaciones emisoras ${ }^{3}$. Los analistas financieros son profesionales especializados en investigar e interpretar la información tanto financiera como no financiera de las empresas, protegiendo también con su actividad la integridad y transparencia del mercado. Estos intermediarios realizan su funciones prestando su "capital reputación" a la corporación con el objeto de que los inversores confíen en la información revelada por ella ${ }^{4}$; actuando así como terceros de confianza o gatekeepers.

$\mathrm{Su}$ actividad consiste en la investigación y recogida de información de las sociedades cotizadas para analizarla, procesarla y transformarla en informes escritos que generalmente contienen predicciones de beneficios

3 J.C. CoFFE. Gatekeeper failure and reform: The challenge of fashioning relevant reforms. Columbia Law School, Center for Law and Economic Studies. Working paper $n^{\circ}$ 237. (2003).

4 J.C. CoffE. Gatekeepers the professions and corporate governance. Oxford. New York: Oxford University Press. (2006). 
de la compañía analizada, estimaciones de precios y recomendaciones objetivas de inversión. Las recomendaciones son el medio que habitualmente usan los analistas para dar a conocer los resultados de sus investigaciones, comunicar sus expectativas acerca del desempeño futuro de una empresa y aconsejar un determinado curso de acción ${ }^{5}$. Tanto los inversores individuales o particulares como los institucionales utilizan estas recomendaciones y predicciones de beneficios para tomar sus decisiones de inversión. De esta forma, la actividad de los analistas influye considerablemente en el proceso de formación de las expectativas de los inversores y en la configuración del precio de las acciones, lo que puede producir un impacto positivo o negativo en el mercado de valores.

De acuerdo con la Securities Exchange Commission de los Estados Unidos en su Reglamento $\mathrm{AC}^{6,7}$ (analyst certification), un analista es cualquier "persona natural responsable de la preparación del contenido de un informe o reporte de investigación que es distribuido por un agente de bolsa o persona asociada". Un informe o reporte de investigación así mismo se define como "una comunicación escrita (incluyéndose las comunicaciones electrónicas) que contiene un análisis de un valor o de un emisor y que proporciona la información razonablemente necesaria sobre la cual basar una decisión de inversión".

En principio, los analistas presentan sus informes a clientes particulares de forma privada y después de un tiempo se hacen públicos. No obstante, también pueden ser difundidos públicamente, mucho más en la actualidad con el desarrollo de las nuevas tecnologías y la existencia de sites en Internet con ese propósito, y con el auge de los $e$-analistas (analistas de inversiones que publican sus informes financieros en Internet).

La mayoría de analistas se especializan en una industria o sector específico, por ejemplo, telecomunicaciones, energía, automóviles o bancario, en una región determinada, un tipo de producto y en un número limitado de acciones (por lo general entre 10 y 15) y, al contrario de lo que se podría pensar, no todas las compañías en el mercado están "cubiertas" por un analista. De las compañías cotizadas, menos de la mitad lo están por dos o más analistas, así que la opinión de un solo analista puede ser crucial para su valoración en el mercado y para las decisiones de los inversores.

Como en todas las profesiones y servicios, existe competencia también entre los analistas, pero ésta es una competencia distinta, ya que normalmente

5 G. López Espinosa \& J. C. Gómez SAla. El valor de las recomendaciones de consenso de los analistas financieros en el mercado de capitales español. Moneda y Crédito. $\mathrm{n}^{\circ} 223$. (2006).

6 U.S. Securities and Exchange Comission. Regulation Analyst Certification, Final Rule, 17 CFR PART 242, Release n 33-8193; 34-47384; File No. S7-30-02. Effective Date, April 14, 2003.

7 Este reglamento pretende promover la integridad de los informes de investigación y la confianza de los inversores por medio de certificaciones y la revelación de información sobre el pago a los analistas. 
un competidor no duplica exactamente los servicios prestados por otro. En el caso de los analistas, una misma empresa puede ser seguida por 5, $10 \mathrm{o}$ más analistas, donde cada uno realiza sus propios reportes, predicciones y recomendaciones. Esto hace que más que en ninguna otra profesión se pueda medir con mucha facilidad el éxito o el fracaso del analista, con una simple comparación entre sus predicciones y el desempeño real de una empresa en el mercado ${ }^{8}$.

Otra característica esencial para determinar la responsabilidad es que los analistas de inversiones no son directamente remunerados por los inversores que usan y confían en sus informes. Por lo general, lo que ocurre es que los departamentos de investigación de las empresas de servicios financieros son subsidiados por otros departamentos, como por ejemplo, el de banca de inversión, situación que crea evidentes conflictos de intereses y que ha sido expresamente regulada?

Finalmente, considerando lo anterior se puede observar cómo el producto final del trabajo de los analistas es la información. Una información que puede ser pública, circular libremente y, en cualquier momento, llegar a perjudicar a un número ilimitado de personas, relacionadas o no con el analista, que confíen en ella y actúen en consecuencia.

\subsection{Contratos y condiciones básicas}

Los analistas financieros del sell-side -investigan y recogen información sobre las sociedades cotizadas en bolsa para sus clientes- por lo general trabajan en los departamentos de investigación de grandes firmas agentes de bolsa que prestan todo tipo de servicios financieros. Para los propósitos de esta investigación sólo nos referiremos a la parte de investigación y análisis financiero de estas empresas que implique una actuación del analista como gatekeeper o tercero de confianza en el mercado.

Los analistas pueden realizar investigaciones, informes o reportes para un cliente en particular con quien han celebrado un contrato de asesoría, consultoría o agencia. En este caso, aunque las partes en el contrato son el analista y el cliente o inversor, es posible que la información llegue a manos de terceros, inversionistas en potencia, que confíen en ella y actúen en consecuencia realizando una transacción.

También pueden realizar reportes sobre el mercado de valores, títulos de renta fija o la economía en general y publicarlos directamente o por medio de terceros, por ejemplo, en páginas de Internet con ese propósito. En este

8 J.C. CofFE. Gatekeepers the professions and corporate governance (Oxford; New York: Oxford University Press, 2006).

9 Jill E. Fisch. The Analyst as Fiduciary: A Misguided Quest for Analyst Independence? Business Law and Director, Center for Corporate, Securities \& Financial Law, Fordham Law School, 2006. 
caso es muy posible que terceros inversionistas individuales o amateurs confíen en dicha información y actúen en consecuencia. Estos dos últimos planteamientos son los que nos interesan para determinar la responsabilidad del analista financiero como tercero de confianza.

Por lo general, en todos los contratos se incluyen cláusulas sobre el riesgo y la posibilidad de pérdida, la no constitución de consejos o recomendaciones de inversión (compra o venta), acerca de que los materiales están basados en información que ha sido obtenida de fuentes que se creen confiables, pero no hay ninguna garantía de su exactitud, la exclusión de la responsabilidad del analista o de la entidad de servicios financieros, según el caso, por cualquier pérdida, daño o perjuicio causado por la información. Analizaremos más adelante cuál es la validez de estas cláusulas y advertencias y qué pasa cuando un tercero, confiando en la información dada por el analista, realiza una inversión y sufre un daño.

\subsection{Independencia y conflictos de intereses}

El tema de conflictos de intereses e independencia de los analistas financieros es uno de los más debatidos y regulados tanto en los Estados Unidos como en la Unión Europea. Los conflictos de intereses han sido culpados de las desviaciones en los informes y recomendaciones de los analistas de inversiones y de mermar el papel del analista como transmisor de información y gatekeeper del mercado de valores ${ }^{10}$.

La implicación de estos profesionales en actividades distintas del análisis, como la banca de inversión, la gran mayoría de las veces influye en la objetividad de sus informes. Un mal manejo de estos conflictos dentro de las empresas de servicios financieros que preparan este tipo de análisis puede dar como resultado estudios e informes sesgados, enviando señales -tanto de forma positiva como negativa-falsas al mercado.

Un ejemplo claro de este sesgo optimista lo tenemos en el caso Enron, hecho notoriamente conocido, donde aún en octubre del 2001, a dos meses de su bancarrota, 16 de los 17 analistas financieros que cubrían dicha empresa mantenían las recomendaciones de compra (A buy o A strong buy). Representativamente la primera agencia en disminuir su calificación a "venta", Prudential Securities, no estaba relacionada con actividades de banca de inversión ${ }^{11}$.

Es evidente que la empresa de servicios financieros no tiene la "libertad" para emitir informes neutros ni mucho menos de venta sobre las inversiones

10 J. E. Fisch. The analyst as fiduciary: A misguided quest for analyst independence? (Fordham University - School of Law, 2006).

11 J.C. Coffe. Undestanding Enron: It's all about gatekeepers, stupid. Columbia Law School, The Center for Law and Economic Studies. Working paper $n^{\circ}$ 207. (2002). 
ofrecidas por sus clientes. Esto haría que dichos clientes acudieran a cualquier otra empresa de servicios financieros que sí les diera estas "ventajas", y que otros posibles clientes no acudieran en busca de sus servicios. Otro aspecto fundamental que lleva a la total falta de independencia del analista es la vinculación de su salario, tanto al mantenimiento o aumento de la cartera de clientes, como al número de transacciones que estos clientes realicen, es decir, depende del desempeño del departamento de banca de inversión de sus firmas empleadoras.

Los conflictos de intereses pueden agruparse en seis grupos, a saber ${ }^{12}:$ a) Conflictos personales; b) Conflictos por comisiones de corretaje; c) Conflictos de banca de inversión; d) Conflictos por el acceso al emisor o presión de las compañías cubiertas; e) Conflictos con el inversor; y f) Conflictos por las recomendaciones de consenso.

Como respuesta a estos conflictos y buscando la mayor transparencia del mercado, las autoridades de los Estados Unidos y de la Unión Europea han adoptado una serie de regulaciones para asegurar la neutralidad de los analistas. La Securities Exchange Commission (SEC) adoptó la Regulación AC (Analyst Certification) ya citada, y el acuerdo llamado Global Settlement, firmado entre las autoridades americanas y las primeras diez firmas de valores de los Estados Unidos. En la Unión Europea, por su parte, el Grupo del Foro sobre Analistas Financieros (Forum Group on Financial Analysts), convocado por la Comisión Europea, propuso también una solución, aunque menos directa, para el tema de los conflictos de intereses.

\section{REGULACIÓN GENERAL Y CódIGOS DE CONDUCTA}

\subsection{Los Estados Unidos de América}

El auge y fortalecimiento de la regulación del analista financiero como tercero de confianza o gatekeeper del mercado tienen su origen en las irregularidades y grandes escándalos financieros que tuvieron lugar en los Estados Unidos entre los años 2001-2002 $2^{13}$.

Sobre las leyes anteriores, simplemente hay que mencionar que rigen la Securities Exchange Act de 1934 y la Securities Act de 1933 para la regulación del mercado de capitales primario (colocación de valores de primera emisión) y secundario (compraventa de valores que ya han sido emitidos en una primera oferta pública o privada). También es importante la Regla 10b-5 promulgada por la SEC, que prohíbe cualquier acto u omisión que resulte

12 J.C. Coffe. Op. cit. Págs. 250 y ss. (2006).

13 Enron, Tyco International, WorldCom y Peregrine Systems, entre otros. 
en fraude o engaño relacionado con la compra o venta de cualquier valor, incluido el abuso de información privilegiada.

El Congreso promulgó la famosa Sarbanes-Oxley $\mathrm{Act}^{14}$, también conocida como la Ley de Reforma de la Contabilidad Pública de las Empresas y de Protección al Inversionista, el 30 de julio del 2002, con el objetivo principal de recuperar lo más rápido posible la confianza en el mercado de valores estadounidense. Específicamente para los analistas, se incluyó la Sección 501 (codificada como la nueva Sección 15D en la Securities Exchange Act de 1934), que exigía que la SEC directamente o por medio de alguna asociación registrada o bolsa nacional de valores, adoptara las reglas necesarias para abordar los conflictos de intereses que pudieran surgir en la elaboración de los informes y recomendaciones de los analistas financieros. Para el cumplimiento de esta norma, la National Association of Securities Dealers (NASD) y la New York Stock Exchange (NYSE) han creado unas normas de conducta que impulsan la independencia de los analistas.

Por otra parte y, con la intención específica de asegurar la independencia de los analistas financieros y reducir las situaciones de conflictos de intereses, ciertas organizaciones ya mencionadas como el New York Stock Exchange o la National Association of Securities Dealers adoptaron regulaciones especiales. En el mismo sentido, el 14 de abril del 2003, la SEC adoptó la Regulación AC (Analyst Certification), que exige a los intermediarios, agentes comerciales y otras personas relacionadas con ellos, incluir en todos los informes de investigación, certificaciones del analista financiero que ha realizado el reporte, sobre la coincidencia exacta de su opinión personal con las opiniones expresadas en dicho reporte.

Adicionalmente existe el acuerdo llamado Global Settlement, firmado en abril del 2003, entre la SEC (Securities Exchange Commission), la NASD ( $N a-$ tional Association of Securities Dealers) y la NYSE (New York Stock Exchange) y, las 10 firmas "top" de valores e inversión de los Estados Unidos ${ }^{15}$. Los bancos aceptaron pagar colectivamente una suma de dinero para distribuirla entre el pago de penalidades, financiación de investigación independiente y promoción de la educación del inversor. Además de los pagos monetarios, el acuerdo busca regular las relaciones entre los departamentos de banca de inversión y de investigación y análisis en las firmas de servicios financieros.

Finalmente, hay que mencionar que el sistema regulatorio de los Estados Unidos está siendo fuertemente cuestionado por el escándalo de Madoff, la mayor estafa de la histotria de Wall Street. Después de tantas señales de

14 Pub. L. $n^{\circ}$ 107-204, 116 Stat. 745.

15 Bear Stearns \& Co. LLC. Credit Suisse First Boston Corp., Deutsche Bank, Goldman Sachs, J.P. Morgan Chase \& Co., Lehman Brothers, Inc., Merrill Lynch \& Co., Inc., Morgan Stanley, Salomon Smith Barney, Inc., y UBS Warburg LLC. 
alarma en el mercado, de quejas sobre las operaciones y de exorbitantes rentabilidades, ¿cómo pudo este fraude pasar inadvertido a la SEC?

\subsection{La Unión Europea}

La Unión Europea no se ha quedado atrás en la regulación del tema, menos aún después del colapso de la multinacional italiana Parmalat en diciembre del 2003. Se ha venido estableciendo una legislación cada vez más especializada para la protección de la transparencia y la confianza en el mercado y un control en la evolución del tema -por ejemplo, el 12 de diciembre del 2006 se generó la comunicación de la Comisión al Consejo y al Parlamento sobre "los informes de inversiones y analistas financieros" donde se hace un balance sobre los avances-.

La llamada reunión informal de ministros de Economía y Finanzas de Oviedo, celebrada en abril del 2002, fue la primera donde se discutió la cuestión de los informes de inversión teniendo en cuenta el caso Enron. Se pidió a la Comisión Europea que estudiara la posibilidad de reglamentar estos informes. Posteriormente la comisión convocó al Grupo del Foro sobre Analistas Financieros (Forum Group on Financial Analysts), donde se recomendó la regulación general con normas mínimas y principios (a diferencia de los Estados Unidos) y la promoción de la autorregulación.

En el mismo sentido, la Organización Internacional de Comisiones de Valores (OICV) (International Organization of Securities Commissioners Technical Committee, IOSCO), publicó unas declaraciones de principios sobre la información financiera corporativa y sobre el manejo de los conflictos de intereses de los analistas de valores del lado de la venta. Estos principios no son vinculantes para los Estados, pero buscan llegar a un consenso sobre la regulación general del mercado de valores y los informes de inversiones.

En cuanto a la legislación europea, siguiendo el plan de acción para los Servicios Financieros, están en vigor la Directiva 2003/6/CE del Parlamento Europeo y del Consejo, de 28 de enero del 2003, sobre las operaciones con información privilegiada y la manipulación del mercado (abuso del mercado); y la Directiva 2004/39/CE del Parlamento Europeo y del Consejo, del 21 de abril del 2004, relativa a los mercados de instrumentos financieros (Directiva MiFID, modificada por la Directiva 2006/31CE).

\subsection{España}

España, además de incorporar las normas comunitarias, también ha procurado actualizar su legislación buscando la transparencia en la información, la protección del inversor y la confianza en el mercado bursátil. Se puede mencionar inicialmente la Ley 44 del 22 de noviembre del 2002, de Medidas de 
Reforma del Sistema Financiero. Esta ley reforma ciertos aspectos de la Ley 24 de 1988 del Mercado de Valores sobre el Régimen de la comunicación de información relevante y del uso de información privilegiada. La ley establece que ninguna persona que ejerza actividades relacionadas con el mercado de valores, incluidos los analistas, puede realizar prácticas que tengan como efecto elevar artificialmente las cotizaciones; regula el "no uso" de información privilegiada en ciertas circunstancias; obliga establecer medidas necesarias para impedir el flujo de información privilegiada entre las diferentes áreas garantizando así su autonomía e independencia, evitando así los conflictos de intereses. En particular sobre este tema se obliga a las entidades a establecer áreas de actividades separadas físicamente dentro de la entidad, barreras de información y elaborar listas con los instrumentos financieros, la información privilegiada y las personas que han tenido acceso a la misma.

En el año 2003 se constituyó la denominada Comisión Aldama, una comisión especial para el Fomento de la Transparencia y la Seguridad en los Mercados Financieros y las Sociedades Cotizadas. Esta comisión concluyó que para el verdadero fomento de la transparencia era conveniente tener un soporte normativo de obligatorio cumplimiento, además de los códigos de buena conducta de los consejos de administración de las sociedades cotizadas, cuyo cumplimiento depende de la libre voluntad de las empresas destinatarias. Como resultado, se promulgó la Ley 26 de 17 de julio del 2003, por la que se modifican la Ley 24 de 1988, de 28 de julio, del Mercado de Valores (LMV), y el texto refundido de la ley de Sociedades Anónimas, aprobado por el Real Decreto Legislativo 1564 de 1989, de 22 de diciembre (LSA), con el fin de reforzar la transparencia de las sociedades anónimas cotizadas. Esta ley regula temas de gobierno corporativo en cuanto a los deberes de información y transparencia así como el deber de los administradores de obrar con lealtad y de no estar implicados en conflictos de intereses.

\subsection{Códigos de conducta}

La actividad del analista financiero ejerce una influencia en el desarrollo del mercado, en la valoración de las empresas y en las decisiones de los inversores, estén o no relacionados mediante un convenio contractual con este profesional. Con una actuación negligente, el analista puede causar daños ilimitados a un número indeterminado de personas alrededor del mundo. Por esto, además de las leyes formales y los organismos de vigilancia, el sector financiero ha reaccionado introduciendo códigos de conducta o éticos que, aunque no son de obligatorio cumplimiento, instan a estos profesionales para tener ciertos comportamientos, fomentan las buenas prácticas, protegen al inversor y juegan un papel importante para determinar cómo debe ser la actuación diligente de un analista al momento de elaborar sus informes. 
Después de los escándalos financieros del 2001 en los Estados Unidos, viendo la desconfianza de los inversores y antes de las fuertes reformas legislativas, las principales empresas de Wall Street y la Securities Industry Association (SIA) adoptaron un código de buena conducta o ético donde establecieron normas para los analistas financieros. Los principales aspectos que trata este código, y sobre los que ya nos hemos referido, son la independencia del analista frente a los negocios de banca de inversión de la empresa donde trabaja y la desvinculación de los salarios de operaciones o transacciones concretas.

Esta iniciativa resultó insuficiente al no establecer mecanismos de sanción ni límites idóneos a las actuaciones del analista. Después de esto, algunas firmas como Goldman Sachs anunciaron que sus analistas harían públicas sus carteras de acciones. Esto tampoco resultó suficiente ya que, aunque fomenta la transparencia, no evita otras actuaciones que llevan a la falta de objetividad. Otras compañías como Merryl Linch, después del escándalo en el 2002 sobre los conflictos de intereses entre los departamentos de banca e investigación, han adoptado medidas concretas más drásticas, haciendo que sus analistas elijan desprenderse de las acciones sobre las que realizan informes, mantenerlas cumpliendo estrictas normas como vender sólo cuando su recomendación sea neutra o negativa, o transferir esas acciones a cuentas gestionadas por terceros ${ }^{16}$.

Algunas asociaciones de analistas y bolsas de valores, como la National Association of Securities Dealers (NASD) y la bolsa de Nueva York, han creado normas más estrictas sobre la revelación de las carteras de acciones y la exigencia de publicación de las situaciones de conflictos de intereses. En febrero del 2002, el Comité de Servicios Financieros de los Estados Unidos hizo pública una lista de normas de conducta para los analistas propuesta por la Bolsa de Nueva York y la NASD en cumplimiento de la Sección 501 de la Ley Sarbanes-Oxley.

En España, el Instituto Español de Analistas Financieros (IEAF) actualizó en junio del 2005 su Código de Ética y Conducta Profesional, de obligatorio cumplimiento para todos sus miembros sin importar si desarrollan su actividad de forma independiente o dentro de una institución. Este código habla sobre la prudencia en la realización de los trabajos, la fundamentación de los informes, la defensa de los intereses del cliente, el respeto a las normas, la independencia, la objetividad y por supuesto, la revelación de los conflictos de intereses.

Por otra parte, más allá de las soluciones locales están las instituciones y asociaciones internacionales que promueven los altos estándares éticos y el registro de los analistas financieros. A diferencia de los abogados o los conta-

16 Raúl Bercovitz Álvarez. La responsabilidad de los analistas de inversiones. Revista de Derecho Bancario y Bursátil. nº 86. 7-54. (2002). 
dores, los analistas de inversiones no necesitan credencial, licencia o registro para ejercer su profesión, lo que crea una ausencia casi total de barreras de entrada. Por esto esta profesión ha seguido los pasos de la contabilidad y ha luchado por tener una credencial profesional similar ${ }^{17}$. La credencial o título de mayor conocimiento a nivel mundial por su antigüedad es el de Chartered Financial Analyst, otorgado por el CFA Institute (Chartered Financial Analysts Institute), después de aprobar una serie de rigurosas pruebas. Los miembros y candidatos de este instituto, además de sus cualificaciones, deben cumplir con el código ético y las normas de conducta profesional.

Existen otras asociaciones más recientes como la Association of Certified International Investment Analysts (ACIIA), de la que el IEAF es miembro. Esta asociación, de forma similar al CFA Institute, además de promover la cualificación de los individuos que trabajan en el sector financiero y de inversiones realizando exámenes y otorgando credenciales, fomenta el buen comportamiento con un código o principios de conducta ética.

\section{LA ACTUACIÓN DE LOS ANALISTAS COMO TERCEROS DE CONFIANZA EN EL MERCADO}

El analista financiero puede considerarse como un intermediario de la información. Sus factores de producción o materias primas incluyen información financiera y contable, así como otro tipo de datos que analiza e interpreta. Toma una información y la transforma en otra, por lo que el producto de su trabajo es también la información. Transmite con sus reportes "señales" e información al mercado que generan en el tercer receptor de la misma una "confianza" -justificada o injustificada-que lo lleva a adoptar una decisión o a realizar una transacción, como consecuencia de la cual puede resultar perjudicado. La información falsa, inexacta o errónea puede ser transmitida por el analista al mercado de forma positiva o de forma negativa (pasiva).

\subsection{El producto de los analistas: la información}

Todas las empresas, especialmente las que están cotizadas en bolsas de valores, divulgan información sobre su situación financiera con el objeto de darse a conocer, de ser mejor valoradas en el mercado y de que los inversores compren sus acciones para financiarse. El mercado de capitales aumenta su eficiencia en cuanto a la fijación de precios y la distribución de capitales de forma directamente proporcional a la cantidad, calidad y disponibilidad de información sobre las inversiones y productos. Los analistas financieros son el principal recurso para obtener esta información ${ }^{18}$. Los inversores

17 J.C. Coffe. 2006. Op. cit.

18 J. L. ORCUTt. Investor skepticism vs. Investor confidence: Why the new research analyst reforms will 
institucionales o particulares (minoristas), cualificados o no cualificados, acuden a los análisis financieros para verificar la veracidad de la información divulgada por las empresas y buscan su análisis e interpretación para tomar sus decisiones de inversión.

Así, sin llegar a influir directamente en una transacción particular, la evaluación positiva de una empresa por parte del analista puede dotar de credibilidad a la información y predicciones divulgadas por la empresa en cuestión.

Los analistas de inversiones son intermediarios financieros que con base en su reputación aseguran a los inversores sobre la calidad de los "signos" que envían las empresas al mercado cuando divulgan su información; hacen en definitiva que los inversores y el mercado en general confíen en dicha información cuando de otro modo no lo harían ${ }^{19}$. Los inversores por su parte, confían en el analista como persona experimentada que tiene un "capital reputación" que no puede arriesgarse a perder por un simple cliente ${ }^{20}$. La eficacia de los mercados de capitales mundiales depende de la confianza del público en general, la confianza a su vez depende de la posibilidad que tiene cualquier inversor de disponer de información completa, relevante y confiable, es decir, depende del nivel de transparencia.

La opinión de un solo analista sobre una acción puede tener una influencia decisiva. Consideremos el mercado norteamericano, donde de los 14.000 valores aproximadamente que se negocian públicamente, únicamente 6.000 están cubiertos por analistas y de éstos, menos de la mitad están cubiertos por más de dos analistas ${ }^{21}$.

Los analistas entonces dan credibilidad y transparencia al mercado a través de sus valoraciones. Si los inversores confían casi ciegamente en lo que dicen estos gatekeepers, ¿qué pasa si sus informes son sesgados, si distorsionan la información para inflar los precios artificialmente o simplemente no son objetivos por tener algún conflicto de intereses detrás? Los analistas, junto con los bancos, agencias de calificación, auditores y abogados entre otros, hacen un control a las empresas en el mercado. Concretamente con sus reportes, recomendaciones o predicciones transmiten información o "signos" al mercado en los que los destinatarios confían, actúan en consecuencia y pueden resultar posteriormente dañados como efecto de la (negligente) falsedad, inexactitud u omisión en la información.

harm investors, 81 Denv. U. L. Rev, 1 (2003).

19 J.C. Coffe. 2006. Op. cit.

20 Después de Enron y los demás escándalos financieros se llegó a la conclusión de que los gatekeepers no siempre buscan proteger su reputación y están dispuestos a arriesgar este capital en ciertas circunstancias. Especialmente en los mercados concentrados pueden considerar que no es indispensable tener un récord impecable sino simplemente que no sea mucho peor que el de sus rivales (Coffee, 2006).

21 J. L. Orcutt. 2003. Op. cit. 
Por otra parte, para los objetivos de esta investigación, es esencial resaltar las cualidades de la información como producto, ya que tiene grandes implicaciones al momento de establecer el régimen de responsabilidad de los terceros de confianza. La información es un bien que circula fácil y rápidamente dentro del mercado y puede pasar de mano en mano a bajo costo causando múltiples daños a una cadena interminable de sujetos. El número de posibles víctimas de una información errónea, falsa o inexacta podría ser potencialmente ilimitado ${ }^{22}$. A diferencia de la mayoría de bienes, no se consume con su uso. Pensemos en los $e$-analistas que están tan de moda y las páginas de Internet donde publican sus informes y recomendaciones, ¿cuántas consultas al día, en el mundo entero pueden tener? ¿en un mes? El analista estaría sometido a una responsabilidad excesiva y lo que es aún peor, completamente indeterminada e inasegurable.

La información muestra entonces varias de las características de los bienes públicos: es non-exclusive, lo que significa que una vez que entra en circulación en el mercado nadie puede ser excluido de su uso; y non-rival, que quiere decir que su uso por parte de una sola persona no disminuye la cantidad de información para los demás. Por esto mismo, la información es convenientemente accesible a los llamados free-riders, que la usan sin haber pagado por ella ${ }^{23}$.

Existe otro inconveniente directamente relacionado con lo anterior en cuanto a que quien produce la información, el analista, generalmente no recibe los beneficios de su uso, es decir, asume todos los costos de producción, pero no se apropia de todas las potencialidades del producto de forma directa. Recordemos que la información es un bien público y para que el sistema funcione hay que mantener un equilibrio entre el productor de la misma y el usuario. Este dilema lo ha creado la nueva regulación para la protección de la independencia de los analistas. El hecho de que las firmas de servicios financieros y los bancos de inversión no puedan presionar a sus analistas, involuntariamente ha hecho que ya no quieran subsidiar el análisis y que un menor número de empresas sean seguidas por los analistas ${ }^{24}$. Haciendo un análisis sencillo, podemos concluir que esto haría que escaseara la información en el mercado, pues a nadie le interesaría producirla sabiendo que no va a recibir lo justo por ella ${ }^{25}$.

22 Pedro del Olmo García. Responsabilidad por daño puramente económico causado al usuario de informaciones falsas. Anuario de Derecho Civil. $\mathrm{n}^{\circ}$ 54. 257-368. (2001).

23 J. Chamber Lin. La provisión de bienes colectivos como función del tamaño del grupo. En Lecturas de teoría política positiva. 153-172. J. M. Colemer. Ed. Instituto de Estudios Fiscales. Madrid. (1991); EVA FRADES DE LA FuENTE. La responsabilidad profesional frente a terceros por consejos negligentes. Dykinson. Madrid. (1999); M. OLson. La lógica de la acción colectiva bienes públicos y la teoría de grupo. R. CAlvet trad. Limusa. México. (1992).

24 J.C. Coffe. 2006. Op. cit.

25 Pedro del Olmo. 2001. Op. cit. 
La información puede transmitirse de forma positiva cuando, por ejemplo, un analista elabora un informe, una predicción de beneficios de la compañía analizada, una estimación de precios y/o una recomendación de inversión. Si ha sido elaborada en cumplimiento de un contrato entre el analista y el inversor, en caso de daños por negligencia se aplicaría claramente la responsabilidad contractual, pero ¿qué pasa cuando no existe un contrato de por medio, ni ninguna relación obligatoria previa entre el analista autor de la información y el inversor que ha sufrido un daño económico a causa de la misma?

También puede haber transmisión negativa o pasiva de información, cuando el analista omite intencionalmente una información. Vamos a suponer que un analista no da cierta información negativa al inversor, porque el emisor es cliente del banco de inversión donde trabaja, o da una recomendación neutra y posteriormente se entera del cambio en la situación financiera de la empresa, pero no lo considera relevante y lo omite manteniendo su recomendación. Elaborando un informe - desviado-y dando su recomendación de compra o de mantener una acción omitiendo información, el analista, profesional y experto en la materia, envía un "signo" positivo al mercado sobre el desempeño de una empresa, signo en que confía un tercero que, como consecuencia, decide comprar sus acciones o mantener las que tenía. Después de unos meses el precio de las acciones disminuye en un $80 \%$, o peor aún, la empresa se declara en quiebra causándole graves daños económicos, ¿es responsable el analista? Lo mismo sucede cuando, por ejemplo, se omite información sobre la calidad de los productos o servicios ofrecidos o el nivel real de riesgo que comporta para el inversor.

\section{LA RESPONSABILIDAD DEL ANALISTA FINANCIERO COMO TERCERO DE CONFIANZA}

La responsabilidad del analista financiero con respecto a sus análisis, predicciones y recomendaciones no está específicamente regulada. Existen, como vimos, regulaciones generales sobre la transparencia en el mercado y la información financiera, además de los códigos éticos y de conducta que habitualmente no son coercitivos ¿Cómo encauzar entonces la responsabilidad del analista financiero cuando actúa como tercero de confianza o gatekeeper? Si confiando en una predicción -que luego resulta errónea o inexacta-, realizamos una cuantiosa inversión y resultamos económicamente dañados, ¿demandaríamos por la vía contractual o extracontractual? La naturaleza de la responsabilidad del tercero de confianza, en nuestro caso aplicada al analista financiero, ha sido muy debatida y se ha argumentado a favor tanto de una como de otra posición. 


\subsection{Marco general}

La responsabilidad por daño económico causado por informaciones erróneas, inexactas y falsas viene de la acción de fraude (deceit o fraud), que busca proteger la formación de la voluntad en los negocios contando con información veraz. Inicialmente esta acción estaba abierta a cualquier caso, incluso sin existir contrato entre las partes, más adelante fue limitada a los casos de dolo ${ }^{26}$. En Inglaterra se siguió estrictamente este parámetro hasta 1964, cuando la Cámara de los Lores cambió su posición reconociendo por primera vez la responsabilidad y posibilidad de indemnización por daños puramente económicos causados negligentemente, con independencia de la existencia o no de una relación contractual ${ }^{27}$, simplemente exigiendo la presencia de una "relación especial" entre las partes. En los Estados Unidos, por el contrario, muchas jurisdicciones habían rechazado esta teoría y no la aplicaban o lo hacían de forma muy laxa.

En el famoso caso Ultramares vs. Touche ${ }^{28}$, donde se discutió la responsabilidad de un auditor por un informe ${ }^{29}$, el famoso juez Cardozo descartó la responsabilidad y creó un límite argumentando que si se hiciera responsable al auditor frente a cualquier usuario y frente a cualquier operación, se le estaría sometiendo a "una responsabilidad por cantidad indeterminada, frente a un número indeterminado de víctimas y durante un tiempo también indeterminado".

Este caso determinó el desarrollo del tema en los Estados Unidos hasta 1960, cuando se dictaron varias sentencias que admitían la responsabilidad por negligencia, y se redactó la Section 552 del Restatement (Second) of the law, que regula la negligent misrepresentation en cuanto al alcance que tiene el deber de cuidado en los casos de daños causados por una información falsa o errónea.

A partir de aquí, la jurisprudencia estadounidense se ha desarrollado teniendo en cuenta esta regulación. En otros países se han ideado propuestas y teorías legislativas y jurisprudenciales para fundamentar la responsabilidad del tercero: responsabilidad contractual y extracontractual, el criterio de la relación especial, la proximidad, la previsibilidad y la asunción voluntaria de responsabilidad. También se ha hablado de los límites a esta responsabilidad y la definición de quiénes son los terceros frente a quienes se es responsable.

26 Derry V. Peek (1888) LR 14 App Cas 337.

27 Hedley Byrne vs. Heller (1963) 2 All E.R. 575.

28 Ultramares vs. Touche, 255 N. Y. 170, 174 N. E. 441 (1931)

29 Los auditores son los gatekeepers clásicos. Los primeros casos de este tipo de responsabilidad implicaron a los auditores y la mayor parte de esta jurisprudencia es aplicable a la responsabilidad de los demás gatekeepers del mercado. 
En cuanto al derecho comparado, aunque el tema no tiene una regulación específica generalizada, sí hay algunos países que consagran ciertas normas especiales o intentan dar respuesta al tema a través de la responsabilidad extracontractual.

\subsection{Panorama general: la responsabilidad contractual y extracontractual}

Es indiscutible que cuando existe un contrato en cumplimiento del cual el analista elabora y transmite un informe, predicción o recomendación de inversión a un inversor, cualesquiera que sean sus cualificaciones, y este último resulta dañado por la inexactitud, falsedad o error en la información - causados por la negligencia en la elaboración-, podemos acudir a la vía de la responsabilidad contractual para el resarcimiento de los perjuicios, teniendo en cuenta las obligaciones, el objeto, límites y términos establecidos en el contrato $^{30}$. El analista en estos contratos está obligado a realizar un análisis objetivo de datos (financieros, contables, comportamiento de mercado, etc.), debe diferenciar claramente los hechos reales de sus opiniones, sin garantizar nunca un resultado determinado de una inversión. Su obligación principal es de medios, es decir, será responsable no por el hecho de que la información en sus reportes o recomendaciones sea errónea o inexacta sino por su negligencia en la elaboración (entre otros la omisión de información, conflictos de intereses, falta de objetividad, deslealtad, uso de información confidencial).

Tenemos claro lo anterior y, como vimos, es reconocido en todos los ordenamientos jurídicos, pero ¿qué sucede cuando no existe una relación contractual entre las partes? ¿O cuando efectivamente sí hay un contrato de por medio, pero quien resulta dañado es un tercero ajeno a la relación? Un analista financiero no puede realizar libremente informes y recomendaciones y publicarlos sin tener ninguna responsabilidad hacia los terceros -normalmente inversores particulares o minoristas sin mucha experiencia- que confían en ellos y actúan en consecuencia, ¿cómo superar la barrera en los ordenamientos que excluyen la indemnizabilidad de los daños puramente económicos por medio de la responsabilidad extracontractual?

Como se expuso anteriormente, muchas han sido las soluciones que se han propuesto para imponer responsabilidad a los terceros de confianza o gatekeepers sin aplicar la responsabilidad extracontractual. Podemos encontrar, entre otras, la existencia de una relación contractual entre informante e informado; la existencia de un contrato tácito de información; la responsabilidad basada en la buena fe y la protección de la confianza infringida; o

30 Teresa Rodríguez de las Heras Ballell. El tercero de confianza en el suministro de información. Propuesta de un modelo contractual para la sociedad de la información. Manuscrito entregado por la autora. (2008). 
la vulneración de derechos subjetivos absolutos. Todos estos mecanismos, a nuestro juicio demasiado forzados, teniendo a la mano el instrumento ideal en la responsabilidad extracontractual, mucho más en los sistemas como el español y todos los descendientes del Código francés, donde hay una cláusula abierta de responsabilidad que da cabida a la reparación de los daños puramente económicos.

\subsection{Efectos del régimen de responsabilidad en el mercado. Nivel óptimo de responsabilidad del analista financiero como tercero de confianza}

El nivel de responsabilidad del analista de inversiones como tercero de confianza es un tema de política jurídica que ha sido objeto de amplias discusiones, por su especial influencia en la disponibilidad de información y consiguiente transparencia del mercado.

No hay duda de la imposición de responsabilidad para todos los casos de dolo. Pero para el resto, ¿cuál es el nivel óptimo de responsabilidad que debe afrontar el analista? ¿Responsabilidad estricta? ¿Negligencia? ¿Deberes voluntarios? Los legisladores normalmente no optan por un nivel o sistema fijo sino por combinaciones que los llevan a la mayor eficiencia económica posible.

El nivel de responsabilidad que el analista tenga que asumir al crear y transmitir una información afecta directamente tanto la cantidad como la calidad de la misma. No es óptimo entonces ningún régimen radical, ni la plena responsabilidad por negligencia del analista en la elaboración de información frente a todas las víctimas previsibles, ni la negación de toda responsabilidad por informaciones negligentemente producidas o comunicadas. La solución intermedia sería hacerlo responsable únicamente frente a un tipo de personas y frente a un tipo de usos de esa información ${ }^{31}$.

También hay que tener en cuenta que en caso de imponer sanciones a los analistas como terceros de confianza o gatekeepers, éstas deben ajustarse al costo de producir y transmitir la información. A mayor responsabilidad, mayores costos de investigación y riesgos legales.

En un régimen basado en el concepto tradicional de culpa se presentarían miles de demandas, y teniendo en cuenta que en general el derecho de daños es costoso y muchas veces inefectivo, hay que pensar en crear incentivos para que los terceros sean prudentes y diligentes, los códigos éticos y de conducta ya estudiados buscan cumplir esta función. Así mismo, inclinarse o no hacia un régimen de responsabilidad estricta y no hacia la negligencia depende de las dificultades del gobierno para implantar un régimen de responsabilidad

31 Pedro del Olmo. 2001. Op. cit. 
por negligencia. Para este tipo de responsabilidad, es necesario que los jueces establezcan los niveles de diligencia adecuados para observar como parámetros.

Por regla general, la responsabilidad estricta tiene un costo: distorsiona las decisiones de los agentes económicos de entrar al mercado como consecuencia del aumento de los honorarios de los gatekeepers. En caso de que el tercero de confianza no pueda trasladar estos costos a los clientes, como es el caso de los analistas de inversiones, simplemente hará que disminuya la oferta de servicios de los gatekeepers y consecuentemente la información.

Es necesario que exista un equilibrio en la responsabilidad del analista financiero para que el sistema funcione. El hecho de buscar la confianza pública en el mercado no se debe confundir con la negación de la responsabilidad de los inversores de hacer inversiones basadas en análisis de alta calidad, en el conocimiento de los riesgos que asumen y el riesgo propio de sus decisiones ${ }^{32}$. Si los analistas son responsabilizados de todas las pérdidas sufridas por los terceros, estos carecerán completamente de incentivos para evitarlas ${ }^{33}$.

Los analistas son básicamente unos pronosticadores y sus predicciones sobre el comportamiento o valor futuro de una empresa con frecuencia son erróneas. El pensar en imponer una responsabilidad estricta al analista, teniendo en cuenta su alto margen de error y la volatilidad del mercado, sería su aniquilamiento total.

En definitiva, lo único cierto es que se debe garantizar que exista la suficiente información en el mercado y que dicha información debe tener algún grado de confiabilidad que dé estabilidad y credibilidad al mercado. La responsabilidad debe ser un instrumento para lograr la eficiencia económica, por lo que corresponde asumirla al agente que provoque un mayor aumento en el bienestar social.

\section{LA RESPONSABILIDAD DEL ANALISTA FINANCIERO FRENTE A TERCEROS: ELEMENTOS Y EXTENSIÓN}

Como hemos visto, la mejor vía para encauzar los casos de responsabilidad del analista, como tercero de confianza, es a través de la responsabilidad extracontractual y, dadas las características de la información como producto, esta responsabilidad debe limitarse de alguna manera. Veremos entonces en este capítulo cuáles son los elementos de dicha responsabilidad y quiénes son los terceros frente a quienes el analista, actuando como gatekeeper, debe responder.

32 S. A. Di PiAzzA, \& R. G. Eccles. Building public trust: the future of corporate reporting. New York. John Wiley \& Sons. n 188. (2002).

33 Eva Frades de la Fuente. La responsabilidad profesional frente a terceros por consejos negligentes. Dykinson. Madrid. (1999). 


\subsection{Elementos de la responsabilidad extracontractual}

\subsubsection{Acción dañosa}

La acción dañosa es la acción negligente, haber elaborado y transmitido una información ${ }^{34}$ de forma negligente. De forma general, se entiende que un comportamiento es negligente cuando no sigue el estándar de conducta establecido; se omite aquella diligencia que exige la naturaleza de la obligación y que corresponde a las circunstancias de las personas, del tiempo y del lugar.

Para determinar cuál es el grado de diligencia exigible, hay que establecer inicialmente quién es el informante. Para nuestro caso el analista es un profesional que actúa en su medio como experto, así que hay que tener en cuenta los parámetros de conducta ética y profesional ya establecidos. También es primordial para el examen especificar qué control ejercía sobre la información; el grado de investigación sobre el asunto y la concreción de dicha información. Si el analista no se comportó en las circunstancias del caso de acuerdo con los mínimos parámetros establecidos, entonces su conducta fue culpable y entra en el campo de lo indemnizable.

El criterio usado aquí básicamente es el de la previsibilidad del daño. Debe existir una relación entre la negligencia y el daño, esta relación se refleja en que el daño podía y debía ser previsto y evitado mediante un comportamiento diligente. Si el daño era previsible, la conducta es negligente. Este criterio, que aunque para otras clases de responsabilidad es eficiente, para la responsabilidad por daños puramente económicos causados por informaciones erróneas, falsas o inexactas, da unos resultados excesivos, pues siempre será previsible que alguna persona confíe en la información transmitida y actúe en consecuencia ${ }^{35}$. Es perfectamente razonable que un inversor confíe en una previsión o recomendación de un experto en el ejercicio de su actividad profesional.

El concepto tradicional de culpa entonces es insuficiente para determinar los casos indemnizables, pues daría cabida a reclamaciones por cualquier daño y sometería a los analistas a una responsabilidad colosal. El tradicional principio neminem laedere incentivaría a que las personas se aprovecharan de una información que no les ha costado nada, para luego someter a responsabilidad a quienes la han producido con altos costos y no han tenido retribución alguna. El medio más eficiente para limitar esta responsabilidad es exigir que el analista tenga un deber de cuidado (duty of care) que cubra al inversor. Con esto, las personas -terceros inversores- frente a quienes

\footnotetext{
34 Conviene destacar que el juicio se basa sobre los datos históricos tanto explícitos como implícitos, nunca sobre el contenido valorativo del mensaje.

35 Pedro del Olmo. 2001. Op. cit.
} 
potencialmente tendría que responder serán determinadas o determinables, así como las transacciones u operaciones en las que se use la información.

Para los sistemas inspirados en el Código francés con una cláusula general o abierta de responsabilidad extracontractual, sabiendo que la culpa no es un elemento suficiente para nuestro caso y buscando un medio para limitar esa "previsibilidad absoluta", se puede acoger la solución propuesta por DEL $\mathrm{OLMO}^{36}$, que parece la más sensata, de desdoblar el contenido de la culpa en la idea de un deber de conducta previo y un juicio de violación de ese deber. Así, este deber de cuidado particular puede ser introducido en el derecho español y los sistemas del mismo tipo. Otros autores ${ }^{37}$ proponen buscar un criterio objetivo basado en un modelo de conducta exigible al analista en su actividad, acudiendo a la legislación mercantil. Con este sistema se buscarían principios generales y normas aplicables a los analistas en las leyes de valores, de competencia desleal y general de publicidad. Pareciera que este método además de estar forzadamente acomodado, crearía muchas restricciones en cuanto a su aplicación según la legislación de cada país.

El deber de cuidado es un requisito más que se exige en los sistemas del Common Law para imponer la responsabilidad extracontractual y se puede definir así:

“... la obligación reconocida por el ordenamiento de comportarse con arreglo a determinado patrón de conducta, en concreto, de comportarse como un honrado padre de familia (reasonable person). Para que exista responsabilidad se exige, pues, que el demandado estuviese bajo el deber de ser diligente respecto del demandante, que el primero haya sido negligente al incumplir el patrón de conducta del hombre razonable (que viene a ser lo mismo que violar el deber de diligencia bajo el que estaba) y que esa acción suya haya causado el daño"38.

Aplicando el deber de cuidado, es coherente hablar de negligencia ya no en sentido general, sino únicamente frente a ciertas personas y frente a determinados daños. Es decir, en un juicio de negligencia lo primero que hay que establecer es si el demandado tenía un deber de cuidado o el deber de comportarse de cierta forma frente al demandante, para después sí entrar a estudiar la negligencia como tal, el daño y la relación causal.

\subsubsection{Daño}

Los daños que habitualmente causa una información errónea, inexacta o falsa son meramente económicos y son los relevantes para este trabajo. Dejamos de

36 Ibid

37 Raúl Bercovitz. 2002. Op. cit.

38 Pedro del Olmo. 2001. 303. Op.cit. 
lado los daños físicos a la persona o a los bienes materiales de la víctima (a la propiedad) y las consecuencias de estos daños. La información financiera en estos casos es proporcionada con el objeto de realizar una transacción en el mercado, una inversión o de forma general participar de cualquier forma en el mundo de los negocios, por lo que los daños se ven reflejados en el aspecto financiero. Así mismo, es claro que los daños económicos están por debajo en importancia que los daños físicos o a la integridad personal y que todos los ordenamientos jurídicos así lo consagran.

Estando al tanto de lo anterior, podemos empezar a hablar de los daños puramente económicos diciendo que tienen una capacidad sorprendente de extenderse, lo que los diferencia de los daños físicos o de un bien material específico. Por esto existe el problema de tener una responsabilidad eventualmente ilimitada con la transmisión de información. Las comunicaciones, el mercado y las relaciones económicas se extienden de forma tan rápida e infinita que se convierten en cadenas incontrolables e inacabables, donde el daño a una sola de estas interrelaciones puede tener consecuencias muy lejanas.

Como ha quedado establecido, el producto del que hablamos, la información en cualquiera de sus formatos, tiene la característica de difundirse rápidamente pudiendo causar una oleada de daños económicos -como se ha demostrado en los distintos escándalos financieros--. Por esto, en muchos ordenamientos no está permitida la indemnización de los daños puramente económicos o está muy restringida, primero porque se sometería a una responsabilidad desproporcionada al analista informante en este caso, y segundo, porque la administración de justicia se vería en graves problemas para atender tal cantidad de litigios. El fondo del asunto es encontrar la mejor forma de limitar la responsabilidad por daños económicos llegando a un equilibrio entre la cantidad y calidad de la información y los participantes en el mercado.

\subsubsection{Relación causal: la confianza en la información}

El nexo o relación causal entre el comportamiento del autor, previsión o recomendación del analista y el daño, perjuicio económico sufrido por el inversor, es el último presupuesto básico de la responsabilidad extracontractual. El analista proporciona cierta información a un sujeto que toma una decisión, por ejemplo, la de comprar acciones en una compañía, confiando en dicha información y sufre una pérdida patrimonial causada por la falsedad, inexactitud o incorrección de la misma.

La relación causal entonces está fundada en la confianza que el inversor dañado tiene en la veracidad o exactitud de la información financiera proporcionada por el analista. Confía de tal forma en esa información que toma 
una decisión de negocios basada en ella y resulta perjudicado. En palabras de RodríGuez de LAS Heras:

“... el vínculo de causalidad no viene marcado por conexiones físicas o materiales sino por apreciaciones subjetivas e indiciarias que conforman una confianza razonable -experiencia del usuario, reputación del informante, advertencias sobre las limitaciones del estudio o de los datos, credibilidad de la información, obligación de contrastar los datos y solicitar una segunda opinión, importancia de la decisión". 39

La confianza en la información da estabilidad y credibilidad al mercado de valores. Pero ¿cuándo ocurre esta confianza? ¿Es siempre razonable y justificada?

La confianza del perjudicado es definitiva para completar la relación causal entre la recomendación y el daño por haberla seguido. Muchas veces podría ser más justo decir que el demandante inversor se causó él mismo el daño por una mala decisión suya ${ }^{40}$. Para la imputación de la responsabilidad es esencial que la confianza del dañado inversor pueda calificarse como justificada o razonable. Si el demandante actuó contra todo lo que aconseja el sentido común, la razón y la prudencia, no puede objetivamente imputarse la desgracia al analista. Tampoco es razonable la confianza cuando el inversor tiene los medios necesarios para comprobar la veracidad de la información teniendo en cuenta su calificación como profesional o experto en la materia. En estos casos se considera que simplemente no hubo confianza o que el perjudicado actuó asumiendo su propio riesgo, por lo que se rompe la causalidad. No se puede conferir al mundo el injustificado derecho de apropiarse sin ningún límite del conocimiento experto o la pericia profesional de los autores de una información.

Para determinar la profesionalidad o cualificaciones de los inversores es interesante la categorización que hizo en su momento el Comité del Reguladores Europeos de Valores (CESR) en el proceso de armonización de las normas de conducta en los mercados de valores dentro del Régimen Europeo de Protección al Inversor, recogida actualmente en la Directiva 34 del 2004 del Parlamento Europeo y del Consejo. De acuerdo con la directiva, las empresas de servicios de inversiones de cualquier índole deben tener en cuenta la naturaleza profesional, los conocimientos y experiencia de la persona a quien se presta el servicio. Se espera que los inversores profesionales estén en capacidad de proteger sus propios intereses así como los de sus clientes, mientras que los demás inversores requieren un nivel de protección que refleje

39 T. Rodríguez de las Heras Ballell. El régimen jurídico de los mercados electrónicos cerrados (eMarketplaces). 34. Marcial Pons. Madrid. (2006).

40 S. Hedley, Tort. Oxford University Press. Oxford. (2006). 
menor experiencia y manejo. Los inversores considerados profesionales se presumen expertos en todos los servicios y productos de inversión, o al menos con los conocimientos y la prudencia suficientes para buscar información y consejo adicionales para las transacciones donde parezca necesario.

En España también podemos acudir al artículo 78 bis de la Ley 24 de 28 de julio de 1988, del Mercado de Valores, modificada en este aspecto por la Ley 47 del 2007, donde también se establecen unos parámetros muy similares para la clasificación de los clientes de las empresas de servicios de inversión en profesionales y minoristas. Por otra parte, además de tener en cuenta los conocimientos y experiencia del inversor, la información -que después resulta errónea, inexacta o falsa- ha debido ser esencial para la toma de la decisión o la realización de la acción del dañado. Si no es así, no parece que podamos atribuir a la supuesta acción dañosa la causación del daño.

Por último, hay que considerar otros dos factores importantes cuando hablamos de la confianza razonable o justificada. El primero es la gratuidad de la información. Podemos suponer que es diferente el grado de responsabilidad que asume un analista cuando da una recomendación y la diligencia que emplea en su elaboración, cuando la proporciona de forma general y gratuita al público, a cuando lo hace en cumplimiento de un contrato particular y recibe una remuneración como contraprestación.

En palabras de Pedro del Olmo:

"En efecto, un informe que se ofrece gratuitamente no es la mejor base para entender que el informante está asumiendo responsabilidad acerca de la corrección del mensaje que emite". ${ }^{41}$

El segundo factor es el momento en que se dispone de la información, por ejemplo, el día en que el analista publica sus recomendaciones en Internet. No se puede analizar si la confianza en la información ha sido o no razonable cuando el dañado ha tomado la decisión antes de tener a la mano y usar la información financiera como base de su decisión. En este caso la información no fue condición necesaria del daño y no existe relación de causalidad.

\section{2. ¿Quiénes son terceros?}

Está claro que el analista tiene una responsabilidad limitada y que no todos los terceros están legitimados para pedir una indemnización por los daños que les hayan podido causar su confianza y difusión de la información creada por el profesional. Para poder imputar responsabilidad por el daño puramente económico, es preciso inicialmente establecer hasta dónde llega

41 Pedro del Olmo. 2001. 349. Op. cit. 
el deber de cuidado del analista demandado. Necesariamente debemos fijar algún parámetro para determinar quién está legitimado por activa.

Para esta tarea, además de tener en cuenta lo estudiado, podemos recurrir al Parágrafo 552 del Restatement (Second) of the law de los Estados Unidos al que ya nos hemos referido. Los requisitos son básicamente dos:

a) Que el perjudicado forme parte del grupo de personas para quienes se elaboró y/o proporcionó la información o se preveía que iban a disponer de ella, y;

b) Que el daño al perjudicado se haya causado al realizar la operación o transacción para la cual se elaboró y/o proporcionó -negligentemente- la información que resulta ser inexacta, errónea o falsa.

En definitiva, los límites de la responsabilidad están en que el tercero perjudicado sin relación contractual alguna debe formar parte del grupo de personas a las que la información iba dirigida y el daño se debió causar en la realización de la operación para la cual dicha información fue elaborada. Quien confía espera razonablemente que el informante esté sometido a un deber de cuidado. Así mismo, el informante debe saber qué uso se le va a dar a la información para de esta forma determinar el grado de diligencia que empleará en su elaboración y comunicación y, por supuesto, la inclusión o no de cláusulas exoneratorias que limiten su responsabilidad.

El tercero inversor que confía, entonces, además de la buena fe exigible en todos los ordenamientos jurídicos debe:

a) Hacer parte del grupo determinado de personas a quienes iba dirigida la información o se preveía iba a ser destinatario de la misma (ser determinado o determinable);

b) Usar la información para la operación o transacción para la cual fue elaborada o para una similar; y

c) Demostrar que su confianza en la información fue justificada o razonable teniendo en cuenta sus calidades profesionales, conocimiento del mercado de inversiones, posibilidades de comprobar la veracidad o exactitud de dicha información y determinar la necesidad de otros análisis o recomendaciones.

Es necesario entonces determinar inicialmente la existencia de un deber de cuidado previo que cobije al tercero dañado. Si efectivamente existe este deber de cuidado, ya podemos entrar a probar y analizar los tres elementos básicos de la responsabilidad extracontractual que hemos estudiado.

\subsubsection{Los inversores}

Los terceros protagonistas de los daños económicos causados por la información inexacta, errónea o falsa proporcionada por el analista, son los inversores - por lo general particulares o minoristas- sin la experiencia ni 
los conocimientos suficientes, que actúan depositando justificadamente su confianza en la información pública procurada por un experto.

De acuerdo con lo anteriormente expuesto, para que el inversor logre una indemnización debe demostrar que forma parte del grupo de personas a las que el analista previó o pudo prever les iba a llegar la información; usar esa información para la transacción para la cual el analista la elaboró o una similar; y demostrar que su confianza en ella era razonable. Posteriormente vendría la prueba de los elementos de la responsabilidad civil extracontractual, es decir, los elementos que hemos señalado a través del trabajo deben ser analizados como un todo y no de forma aislada.

\subsubsection{Las empresas analizadas}

Las empresas analizadas son un caso especial y se encuentran dentro de los terceros que pueden resultar perjudicados. La difusión de informes o predicciones sobre su comportamiento futuro en el mercado y las consecuentes recomendaciones de inversión pueden afectar el buen nombre y prestigio de la compañía y tener un efecto decisivo en el precio de sus acciones.

Como se explicó, el resultado del proceso de análisis de la información financiera condiciona en gran parte las decisiones de los inversores y, pensando en la sumatoria de todas estas decisiones, se puede producir un impacto importante en el mercado de valores ${ }^{42}$. El analista de esta forma juega un papel importante en la determinación del precio de las acciones. La empresa en sí misma no es quien confía en la información y la usa en una transacción, pero sí sus posibles inversores, pudiendo ella resultar directamente perjudicada por una información inexacta, errónea o falsa.

Los legitimados para pedir una indemnización serían la empresa misma, sus dueños u otra parte que demuestre su interés directo. Como es evidente, se deben probar también todos los presupuestos de la responsabilidad extracontractual ${ }^{43}$.

\section{LÍMITES A LA RESPONSABILIDAD DEL ANALISTA FINANCIERO}

Como se ha señalado, deben existir ciertos límites para la responsabilidad del analista financiero, tomando en consideración que al estar generando información, ésta puede llegar a un número ilimitado de personas. Por ello,

42 Jorge M. Larrán \& W. Rees. Propiedades de los pronósticos de beneficios realizados por los analistas financieros: una aplicación al caso español. Revista Española de Financiación y Contabilidad. $\mathrm{n}^{\circ}$ 101 (1999).

43 Sobre el tema véase la sentencia de la Corte de Apelaciones de París de 30 de junio del 2006 en el asunto "LVMH vs. Morgan Stanley". 
los analistas deben saber específicamente o poder determinar a quién va dirigida la información que producen y en qué transacción o negocio va a ser usada, con el objeto de saber hasta dónde llega su responsabilidad, la diligencia con que elaboran los informes y recomendaciones y la limitación de su responsabilidad mediante cláusulas de exoneración.

\subsection{Cláusulas de limitación, exclusión o disclaimers}

A través de estas cláusulas el analista puede ajustar el grado de responsabilidad que asume, teniendo en cuenta que no puede fácilmente controlar hasta dónde llega ni quiénes son los usuarios de la información que produce. La doctrina ha señalado que su admisión refleja el interés general de la sociedad en el intercambio de información económica. Estas cláusulas son esencialmente contractuales, sin embargo, para nuestro caso podría cumplirse este requisito admitiendo ciertos hechos como fórmulas de manifestación del consentimiento (e.g. condiciones generales al entrar en una página web) ${ }^{44}$.

Inicialmente hay que anotar que sin tener en cuenta el tipo de responsabilidad contractual o extracontractual, estas cláusulas son siempre nulas en los supuestos de dolo, culpa grave o mala fe. Tampoco son válidas cuando contradicen una norma imperativa o limitan de forma inadecuada los derechos legales del consumidor.

La primera vez que la Cámara de los Lores reconoció la posibilidad de reclamar por la vía extracontractual las pérdidas puramente económicas de un tercero ${ }^{45}$ causadas por su confianza en la información proporcionada por un experto, negó el resarcimiento con base en la existencia de una cláusula exoneratoria de responsabilidad incluida por el profesional en el informe. Sin embargo, actualmente la tendencia general en todos los ordenamientos es el reconocimiento de la posibilidad de limitar o excluir la responsabilidad frente a los daños económicos con ciertas restricciones.

Tiene sentido hablar de exoneración cuando existe un deber de cuidado y este deber de cuidado que pesa sobre el analista es un deber legal, es decir, si fuera una obligación voluntaria, siempre podría excluir o limitar su responsabilidad frente a terceros. Antes de estudiar la validez de dichas cláusulas, hay que determinar que existe un deber específico de cuidado, este deber se incumple o viola resultando en la responsabilidad que se quiere excluir con estas cláusulas. Son aceptadas de forma general cuando la confianza del tercero no estaba justificada. Para que una cláusula de exoneración, contenida o no dentro de un contrato, sea efectiva, es necesario que la otra parte -el inversor-tenga conocimiento de la existencia de la misma.

44 T. Rodríguez de la Heras. (2006). Op. cit.

45 Hedley Byrne vs. Heller [1963] 2 All E.R. 575. 
Un punto interesante son las "señales" que una cláusula de exoneración o limitación de la responsabilidad pueden enviar al mercado o al usuario de la información. Podríamos admitir que cuando una información las contiene, disminuye la confianza razonable que el destinatario tendría en ella. En otras palabras, si un informante no asume responsabilidad por lo que dice, pues expresamente está excluyendo su responsabilidad, es razonable dudar sobre la veracidad, exactitud o corrección de dicha información. En caso de juicio, podría constituir una causal de confianza no justificada.

Otro límite de la responsabilidad son los casos en que la recomendación o predicción sea proporcionada gratuitamente por el analista fuera del ámbito de su actividad profesional, como en una reunión social informal, este tipo de información a pesar de ser negligente no acarrea ninguna responsabilidad para el analista. Sin embargo, hay que atenerse a las circunstancias de cada caso, pues el contexto puede ser engañoso, en cuanto que el analista puede ejercer su profesión en un partido de golf con un cliente o en una cena de negocios ${ }^{46}$.

Es dudosa también la responsabilidad del analista cuando sus predicciones o recomendaciones resultan inexactas o erróneas por haberse basado en información viciada proporcionada al analista por la misma empresa o sociedad objeto de análisis o por sus auditores. Surge la duda de hasta dónde llega el deber del analista de confirmar la veracidad o exactitud de la información, pero no parece que debiera imputársele toda la responsabilidad. Podría ser un caso de concurrencia de culpas.

Finalmente hay que precisar que el insertar una cláusula de exoneración de responsabilidad no sustituye la obligación por parte del analista de revelar sus situaciones de conflicto de intereses.

En definitiva los límites a la responsabilidad tienen como fin mantener un equilibrio entre el grado de responsabilidad asumido por una parte y la calidad y cantidad de información en el mercado, es decir, su transparencia, y en últimas, de proteger a los consumidores y asegurar un equilibrio de las prestaciones en las relaciones económicas.

\subsection{Advertencia o "warning"}

Las advertencias o warnings son, como su nombre indica, simplemente eso, una advertencia unilateral general sobre algún riesgo presente en el desarrollo de cierta actividad. Las podemos encontrar en casi todos los lugares y para la mayoría de actividades, incluyendo el análisis financiero y de inversiones.

Raúl Bercovitz. 2002. Op. cit. 
El derecho de daños basado en la negligencia impone la obligación general a todas las personas de no hacer (acto u omisión) lo que previsiblemente causará un daño o pérdida a alguna persona. Estas advertencias se usan de forma general para prevenir ese daño, pero no constituyen en realidad una exoneración de responsabilidad, y en caso de negligencia, el culpable debe responder. Sin embargo, pueden poner alerta al inversor destinatario de la información, para aplicar con esmero el deber de cuidado y limitar consecuentemente la razonabilidad de su eventual confianza (reliance) en la exactitud o veracidad de dicha información, pudiendo por tanto llegar a afectar el nexo causal.

Los analistas o empresas de servicios financieros hacen advertencias generales para todos sus productos y servicios que habitualmente se refieren al riesgo de una posible pérdida, la no garantía sobre la exactitud de la información y posibilidad de cambio repentino. 


\section{CONCLUSIONES}

Esta investigación analiza la responsabilidad del analista de inversiones cuando éste actúa como tercero de confianza o gatekeeper en el mercado; sus funciones y actividades básicas, así como su regulación general, tanto por medio de leyes estatales como de códigos éticos y de conducta. Se estableció la actuación del analista como gatekeeper, básicamente por su labor de transmisor de información y signos al mercado y la consiguiente confianza que genera hacia terceros que actúan con base en dichos datos. El análisis comparado sugiere que la responsabilidad extracontractual es el instrumento más eficaz para tratar estos casos, siempre y cuando se exija al analista un deber de cuidado específico que cubra al inversor. Asimismo, que para que exista responsabilidad del analista, el tercero perjudicado debe formar parte del grupo de personas a las que la información iba dirigida o se preveía que podía obtenerla. Finalmente se estableció quiénes son los terceros legitimados para pedir un resarcimiento y cuáles son los límites a la responsabilidad del analista.

De esta forma, el análisis comparado realizado permite llegar a las siguientes conclusiones generales, dejando la puerta abierta para futuras investigaciones sobre esta misma línea:

1. Los analistas financieros son profesionales especializados en investigar e interpretar la información financiera. El resultado final de su trabajo se plasma en informes escritos que generalmente contienen predicciones de beneficios de la compañía analizada, estimaciones de precios y recomendaciones objetivas de inversión. Sus obligaciones son de medios, no de resultados. Estos informes y recomendaciones pueden eventualmente llegar a manos de terceros inversores que no tienen ninguna relación contractual con el analista. Teniendo en cuenta las calidades del experto, estos terceros confían en dicha información y toman una decisión o realizan una transacción resultando dañados por la inexactitud, incorrección o falsedad en la información.

2. Los conflictos de intereses han sido culpados de las desviaciones en los informes y recomendaciones de los analistas de inversiones y de limitar su papel como transmisores de información y gatekeepers del mercado de valores. Estos conflictos suceden fundamentalmente por la implicación de estos profesionales en actividades distintas del análisis.

3. Los gobiernos de los Estados Unidos y la Unión Europea han creado diferentes regulaciones para intentar asegurar la independencia y objetividad de los analistas. La legislación europea lleva poco tiempo en vigor, futuras investigaciones evaluarán cuáles han sido sus resultados.

4. Los códigos éticos y de conducta han cumplido un papel aún más importante que la regulación directa. Las asociaciones de analistas y bolsas de valores han creado normas estrictas de forzoso cumplimiento y cada vez son 
más valorados los exámenes de acreditación y el registro de los analistas en las instituciones internacionales, que muy posiblemente será obligatorio en el futuro. El tema ya está presente y fue debatido por la Comisión Europea a raíz del informe del Grupo del Foro y los principios de la OICV.

5. El producto de la actividad del analista es la información que transmite tanto de forma positiva como de forma negativa. Los "signos" que envía al mercado pueden tener una influencia decisiva en cuanto a las inversiones y en cuanto al precio o valoración de las empresas. La información -en la que confían los terceros- es un bien que circula fácil y rápidamente dentro del mercado mundial y puede pasar de mano en mano a bajo costo causando múltiples daños a una cadena interminable de sujetos. Es así como el número de posibles víctimas de una información errónea o inexacta podría ser potencialmente ilimitado.

6. Teniendo en cuenta las características del producto de los analistas -la información-, se puede afirmar que su responsabilidad como terceros de confianza o gatekeepers es especial y debe ser limitada. Se han propuesto muchas soluciones para imponerle responsabilidad, encontrando que el mejor mecanismo es encauzarla a través de la responsabilidad extracontractual, pero dejando a un lado la culpa y la previsibilidad como factores determinantes y exigiendo la existencia de un deber de cuidado (duty of care) específico que cubra al inversor.

7. El parámetro para determinar hasta dónde llega el deber de cuidado del analista está en que el tercero perjudicado debe formar parte del grupo de personas a las que la información iba dirigida o se preveía que podía obtenerla (determinado o determinable), y que el daño se cause en la realización de la operación para la cual dicha información fue elaborada o en una similar. Además, el tercero que busque un resarcimiento debe probar que su confianza en la información fue justificada o razonable. Los potenciales terceros que pueden resultar dañados por la información son los inversores y las empresas analizadas.

8. Son válidas las cláusulas de limitación de responsabilidad o disclaimers, a excepción de los supuestos de dolo, culpa grave o mala fe y cuando contradicen una norma imperativa o limitan de forma inadecuada los derechos legales del consumidor. 


\section{BIBLIOGRAFÍA}

Agrawal \& M. A. Chen. Analyst conflicts and research quality. Paper n ${ }^{\circ}$ RHS-06-042, Robert H. Smith School of Business, University of Maryland. (2005).

Geoffrey F. Aronow \& Ehrman LlP. Heller. You are your brother's keeper: The increasing costs of aiding the misconduct of others. (2005).

W. H. BeAver. Financial reporting: an accounting revolution ( $3^{\mathrm{a}}$ ed.). Upper Saddle River: Prentice Hall. (1998).

A. Betancur Rodríguez. Enron: escándalo y tragedia. Política Exterior. $n^{o} 114.91-100$. (2006).

Raúl Bercovitz Álvarez. La responsabilidad de los analistas de inversiones. Págs. 7-54. Revista de Derecho Bancario y Bursátil. 86. (2002).

Fernando Caballero de la Sen. Compliance con Sarbanes-Oxley: un buen comienzo para implantar en la práctica una gestión global de riesgos bajo COSO II. Auditoría Interna. $n^{\circ} 78 .(2006)$.

J. Chamberlin. La provisión de bienes colectivos como función del tamaño del grupo. En J. M. Colemer (Ed.), Lecturas de teoría política positiva (153-172). Madrid. Instituto de Estudios Fiscales. (1991).

S. CHOI. Market lessons for gatekeepers. Northwestern University Law Review. 92(3). (1998).

J. C. CoffeE. Undestanding enron: It's all about gatekeepers, stupid. Working paper $\mathrm{n}^{\mathrm{o}} 207$. Columbia Law School. The Center for Law and Economic Studies. (2002). Gatekeeper failure and reform: The challenge of fashioning relevant reforms. Working paper $\mathrm{n}^{\circ}$ 237. Columbia Law School. The Center for Law and Economic Studies. (2003). Gatekeepers the professions and corporate governance. Oxford; New York. Oxford University Press. (2006).

Pedro del Olmo García. Responsabilidad por daño puramente económico causado al usuario de informaciones falsas. Anuario de Derecho Civil. 54(1). 257-368. (2001).

S. A. Di Piazza y R. G. Eccles. Building public trust: the future of corporate reporting. New York. John Wiley \& Sons. 188. (2002).

Alejandro Fernández de Araoz. La responsabilidad civil de los analistas de inversiones en Francia: comentario a la sentencia de la Corte de Apelaciones de París de 30 de junio del 2006 en el asunto "LVMH/Morgan Stanley". [Versión Electrónica] Revista de Derecho Bancario y Bursátil. 4. (2006).

G. FerRARINI \& P. GiUdici. Financial scandals and the role of private enforcement: the parmalat case. Law Working Paper $\mathrm{n}^{\circ} 4^{\circ}$. European Corporate Governance Institute. (2005).

J. E. Fisch. The analyst as fiduciary: a misguided quest for analyst independence? Fordham University. School of Law. (2006).

Eva Frades de la Fuente. La responsabilidad profesional frente a terceros por consejos negligentes. Madrid. Dykinson. (1999).

E. García Meca \& I. Martínez Conesa. El tráfico de información privilegiada: Evidencias y regulaciones empresariales. Partida Doble. 167. (2005).

M. N. García Santos. Análisis del impacto de la regulación financiera. Evaluación de Políticas Públicas ICE. $\mathrm{n}^{\circ}$ 836. 51-74. (2007). 
E. García Meca \& Jorge M. Larrán. La relevancia de la información no financiera en la estrategia empresarial de divulgación voluntaria: percepciones empresa-analista sobre su utilidad. Revista Valenciana de Economía y Hacienda. n 12. 127-148. (2004).

E. García Meca \& J. P. SÁnchez Ballesta. Influencia de la empresa en los errores de predicción de los analistas financieros: un estudio metaanalítico. Revista Española de Financiación y Contabilidad. 127. (2005).

J. M. GarReta Such. La responsabilidad de los auditores por no detección de fraudes y errores. Madrid. Marcial Pons. Ediciones Jurídicas y Sociales. (2002).

G. A. Giroux. Financial analysis: a user approach. Hoboken NJ. Wiley. (2003).

S. I. Greenbaum \& A. V. Thakor. Contemporary financial intermediation ( ${ }^{\mathrm{a}} \mathrm{Ed}$.). Amsterdam. Elsevier Science. (2007).

A. Hamdani. Gatekeeper liability, discussion paper $n^{\circ} 442$. Harvard Law School. John M. Olin Center for Law, Economics and Business. (2003).

S. Hedley. Tort. Oxford: Oxford University Press. (2006).

H. Hellwig. The US concept of corporate governance under the Sarbanes-Oxley act of 2002 and its effects in Europe. ECFR, 3. (2007).

John JACob, Steve Rock \& David P. WeBer. Do analysts at independent research firms make better earnings forecast. Leeds School of Business y University of Colorado at Boulder. Social Science Research Network. (2003).

REINIER H. KRAAKMAN. Gatekeepers: the anatomy of a third-party enforcement strategy. Journal of Law, Economics and Organization. 2(1). (1986).

P. R. Krugman. The great unravelling: From boom to bust in three scandalous years. London. Allen Lane. (2003).

Jorge M. Larrán \& W. Rees. Propiedades de los pronósticos de beneficios realizados por los analistas financieros: una aplicación al caso español. Revista Española de Financiación y Contabilidad. 101. (1999). Private disclosure in the spanish capital market: Evidence from financial analysts and investor relations directors. Spanish Journal of Finance and Accounting. 115. (2003).

G. López Espinosa y J. C. Gómez SAla. El valor de las recomendaciones de consenso de los analistas financieros en el mercado de capitales español. Moneda y Crédito. 223. (2006).

G. López Espinosa \& J. J. Marhuenda Fructuoso. ¿Cómo afectan cambios en el consenso y la dispersión en la valoración de activos? Revista Española de Financiación y Contabilidad. 129. (2006).

R. Michaely \& K. L. Womack. Conflict of interest and the credibility of underwriter analyst recommendations. Review of Financial Studies. 12(4). (1999).

T. M. J. MöLLERs. Creating standards in a global financial market - the Sarbanes-Oxley act and other activities: What europeans and americans could and should learn from each other. European Company and Financial Law Review. 4(2). (2007).

C. I. Muñoz Colomina. Los paralelismos del caso Enron y el caso Parmalat: del escándalo americano al escándalo europeo. AECA. 73. (2005).

J. O'BRIEN. Governing the corporation: Regulation and corporate governance in an age of scandal and global markets. Chichester. John Wiley \& Sons. (2005). 
M. Olson. La lógica de la acción colectiva, bienes públicos y la teoría de grupos. (R. Calvet trad.). México. Limusa. (1992).

J. L. ORCutT. Investor skepticism vs. Investor confidence: Why the new research analyst reforms will harm investors. 81 Denv. U. L. Rev, 1. (2003).

A. F. Pantaleón Prieto. La responsabilidad civil de los auditores: extensión, limitación, prescripción. Madrid. Civitas. (1996).

F. PARTNOY. Strict liability for gatekeepers: a reply to professor Coffee. Paper ${ }^{\circ} 5$. University of San Diego School of Law, Law and Economics Research Paper Series. (2004).

S. Pellegrini. La relación entre el anonimato del inversor, la formación de los precios y la liquidez. Bolsa de Madrid. 142. (2005).

J. Pons Novell. Obstinación, reputación y efecto rebaño. Revista de Economía Aplicada. 11(32). (2003).

T. Rodríguez de las Heras Ballell. El régimen jurídico de los mercados electrónicos cerrados (e-Marketplaces). Madrid. Marcial Pons. (2006). El tercero de confianza en el suministro de información. Propuesta de un modelo contractual para la sociedad de la información. Manuscrito entregado por la autora. (2008).

José Luis Sánchez Fernández de Valderrama. Contabilidad, transparencia y gobierno corporativo. Análisis Financiero. 90 n Extraordinario sobre "Corporate Governance". (2003).

La importancia de las NIC/NIIF para el análisis financiero. Noticias de la Unión Europea. 259-260. (2006).

J. L. Solís Céspedes y A. Pumarino García-Agull. Control interno financiero: Ley SarbanesOxley, primer año de aplicación y situación actual en España. (2006). 